\title{
Foreword
}

\section{Frank Biermann}

Public-private partnerships for sustainable development are today widely seen as the most prominent outcome of the 2002 World Summit on Sustainable Development in Johannesburg, South Africa. At that time, governments could not agree on major new legislative initiatives to mitigate global environmental change and to advance sustainable development. Instead, they opted to focus on the implementation of existing policies and on the support of partnerships between governments, civil society, business and other societal actors. These partnerships were eventually registered with the United Nations and became known as the 'typeII outcomes' of the Johannesburg Summit, as opposed to the traditional 'type-I' outcomes such as treaties or other major intergovernmental initiatives, which were not achievable then. Several hundred of such 'partnerships for sustainable development' have been agreed before, during and in the few years after the Johannesburg Summit.

While the idea of public-private partnership at the global level was not new in 2002, the high number of the newly agreed partnerships, as well as the prominence and, in parts, enthusiasm that surrounded this mechanism of global governance, was surely unprecedented. Recently, the Voluntary Initiatives for Sustainable Development Goals and International Cooperative Initiatives in the context of post-2015 climate governance have made these governance mechanisms even more prominent.

Yet, the eventual role and relevance of partnerships remain open to debate till today. Some observers view the new emphasis on public-private partnerships as problematic, since voluntary public-private governance arrangements might privilege more powerful actors, in particular 'the North' and 'big business', and consolidate the privatization of governance and dominant neo-liberal modes of globalization. Also, some argue that partnerships lack accountability and (democratic) legitimacy. Yet others see public-private partnerships as an innovative form of governance that addresses deficits of interstate politics by bringing together key actors of civil society, governments and business. In this perspective, public-private partnerships or similar governance networks for sustainable development 
are important new mechanisms to help resolve a variety of current governance deficits. In many of these normative debates the rather broad concept of partnership (and various articulations thereof) is necessarily reduced to a few particular meanings and cases in order to make sense of the complex reality.

It is precisely this problem that Ayşem Mert's important contribution to the study of partnerships addresses. Instead of examining particular articulations and examples of partnerships, it aims to take in all their meanings for various actors and their function for several governance practices and discourses. On the one hand, it places the concept of partnership in its various historical contexts such as business and public administration, international relations, transnational governance, globalization and legal studies. On the other hand, it uses a large- $n$ database, expert surveys, and in-depth interviews to examine in detail what partnership and the United Nations partnership regime mean for various parties involved in their social construction and international negotiation. By doing so it reveals why the concept is so attractive to decision-makers and policy practitioners alike. In the final analysis this book provides a detailed theoretical examination of these novel governance arrangements.

In this sense, this volume is a major contribution to the Netherlands Shifts in Governance research programme and a follow-up to the Partnerships for Sustainability project at the VU University Amsterdam, which started in 2005. In the earlier work of this project, detailed empirical analyses were conducted regarding specific questions of the emergence, influence and legitimacy of sustainability partnerships. Notably, our 2012 analysis of the more than 300 partnerships for sustainable development agreed around the 2002 Johannesburg Summit showed that while partnerships have been portrayed by the United Nations as mere implementation instruments for global sustainability goals, they have also a strong political dimension. The negotiations that resulted in partnerships were marked by profound contestations over partnerships between different governments, business representatives and civil society delegations. This process resulted in a definition and operationalization of the partnership idea that was heavily influenced by powerful actors such as the United States or business interests. While the resulting institutional framework for partnerships was sufficiently vague to allow for the inclusion of many divergent interests, the insufficient monitoring and reporting requirements placed limits on the effectiveness of partnership governance from the very beginning. Analysing the Johannesburg partnerships as the outcome of a political bargaining process rather than the functional answer to various governance demands, opens up the possibility of addressing the question of performance and broader impacts beyond a narrow focus on 
problem-solving effectiveness. This timely book follows up on these results by asking crucial critical questions, for instance how and why partnerships have become the designated governance mechanism to solve environmental problems, what conflicts have settled into the logic of the partnerships regime, and how they normalize and legitimize certain rationales, symbolic orders, or modes of organization over others. Thus, the hegemonic struggles during their negotiations are key to this analysis.

In addition to highlighting the political nature of the United Nations partnership regime, our earlier research also addressed the question of functional and geographic distribution of partnerships for sustainable development. Here we found that - in contrast to many functionalist accounts - partnerships are not necessarily filling functional gaps. They also do not necessarily emerge in the geographic spaces where the demand for partnerships is greatest. Policy network theories go a long way in explaining the geographic dimension of emergence, with partnerships emerging in countries that are member to many international organizations. However, network theories do not seem to be applicable to the participatory dimension of partnerships. While the representation of nonstate actors is considerable, most partnerships are still led by traditional actors in international relations. Some evidence for an institutional explanation for partnership distribution can be found in the fact that partnerships are often active in issue areas that are already densely populated by international law and agreements. However, no prevailing organizational model or best practice could be identified for the overall process around partnerships. Mert now fundamentally problematizes the existing win-win narrative and positive connotations of partnerships by exposing the roots of the concept in liability in business law and the relationship it has with the concept of corporation in the globalizing world political economy. As an explanation, she argues that certain transformations that are taking place in global politics is reflected in partnerships, and that these can be traced when seen as discursive practices.

Finally, with regards to the question of legitimacy, our earlier research inquired whether public-private partnerships can be regarded as democratic, and whether they fulfil core democratic values, such as participation, accountability, transparency and deliberation. We have concluded that their democratic credentials are weak in terms of incorporation of core democratic values, that they consolidate rather than transform asymmetrical patterns of participation between North and South, between established and marginalized groups, and between state and non-state actors. While Johannesburg partnerships appear to encourage user participation, it remained unclear how substantial the involvement of local stakeholders in decision-making has become. Mert continues this line 
of inquiry by adding the numerous democratic imageries that the partnership regime is embedded in. She asks which discourses mediate our understanding of partnerships, and how participatory democracy has been one of the dominant discourses in developmental and environmental governance architectures. The promise of democratic participation, as she convincingly argues, legitimizes numerous problematic practices such as inclusion of contested technologies into the sustainability debates. Our finding (that the implications of technological improvements are not straightforward, as different technologies have varying implications for the autonomy, flexibility and self-reliance of communities) is the basis of her analysis of developmentalism.

In sum, this volume is an important and timely step forward in our understanding of the emergence and legitimacy of public-private partnerships for sustainable development. The book's contribution is both theoretically refreshing and innovative and empirically well-grounded in a deep analysis of major global discourses. Given the still ongoing discussions on multisectoral partnerships in the UN system, this book offers important new perspectives on this partnership idea that will be valuable for both political theorists and policy practitioners.

Frank Biermann VU University Amsterdam, the Netherlands; Lund University, Sweden 